\title{
Genital diseases awareness in young male students: Is information necessary to protect them?
}

\author{
Nicola Mondaini ${ }^{1}$, Mauro Silvani ${ }^{2}$, Teo Zenico ${ }^{3}$, Fabrizio Gallo ${ }^{4}$, \\ Franco Rosso ${ }^{4}$, Tommaso Cai ${ }^{1}$, Gianni Ughi ${ }^{5}$, Pasquale Scarano ${ }^{6}$, \\ Vincenzo Orlando ${ }^{7}$, Riccardo Bartoletti ${ }^{1}$ \\ ${ }^{1}$ U.O. Urology, S. Maria Annunziata Hospital, University of Florence, Italy; \\ 2 Department of Surgery, Division of Urology, Degli Infermi Hospital, Biella, Italy; \\ ${ }^{3}$ U.O. Urology, Morgagni Pierantoni Hospital, Forlì, Italy; \\ ${ }^{4}$ Department of Surgery, Division of Urology, San Paolo Hospital, Savona, Italy; \\ ${ }^{5}$ U.O. Urology, Morgagni Pierantoni, Ferrara, Italy; \\ ${ }^{6}$ U.O. Urology, Civile Hospital, Rimini, Italy; \\ ${ }^{7}$ Stabilimento Chimico Farmaceutico Militare, Florence, Italy.
}

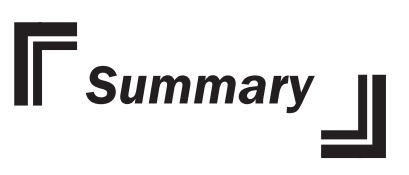

Introduction: Few studies on the prevalence of male sexual diseases are currently available due to difficult application of observational studies or andrological disease prevention campaigns on large series of apparently healthy subjects. The medical check-up linked to compulsory military service represented in Italy a valid tool for epidemiological and observational study for 18 year old boys from 1861 to 2004. The stopping of compulsory military service and its related medical check-up could have determined an important social impact in terms of a lower level of attention and care on male genital/sexual diseases. The aim of the present observational study was to check the prevalence of genital/sexual diseases among young male high-school students and promote an alternative campaign of information among young students.

Methods: A prospective observational analytical study on young male students was conducted by 6 urological centres. Genital and sexually transmitted diseases were presented with slides to students in a general assembly. Some students were then counselled and filled out a short questionnaire on their lifestyle.

Results: 12,535 students (10,432 males-83.6\%) followed the presentation. and 4,897 males (46.7\%) decided to be checked-up by the urologist and out of them 1554 (31.7\%) presented relevant andrological diseases. Five-hundred students completed the questionnaire concerning their lifestyle. Many of them had not yet experienced condom use during sexual intercourse (27.8\%). Drug abuse was reported by $39.6 \%$ of subjects and alcohol consumption in $80.8 \%$ of them. Conclusions: These data suggest the need for a national information campaign on male sexual disorders to promote sexual health.

KEY WORDS: Sexual dysfunctions; Klinefelter syndrome; Sexually transmitted diseases; Sexual health awareness; Fertility; Andrologic disease; Genital diseases; Young male students.

\section{INTRODUCTION}

Women are currently well informed and adequately counselled for both gynecological and sexually transmitted diseases. Moreover womens' perception of "body health" is more accurate and diligent than in men (1). The excess of reporting minor physical morbidity and affective disorders is probably related to specific subjective behaviours but 
could be also related with confounding variables such as age, race, unemployment, marital status, income, social class and education (2). Men are conversely oriented to underestimate their symptoms and maintain a more practical lifestyle (3). Although systemic and hereditary diseases could be easily diagnosed by either the General Practitioner or health care non-invasive diagnostic tools such as ultrasonography, new-born medical screening and genome analysis, genital and sexual disorders remained often undiscovered and untreated (4). Few studies on the prevalence of male sexual diseases are currently available due to difficult application of observational studies or andrological diseases prevention campaigns on large series of apparently healthy subjects. The medical checkup linked to compulsory military service represented in Italy a valid tool for epidemiological and observational study for 18 years old boys from 1861 to 2004. Previous studies on a series of 80,000 young males evidenced a $40 \%$ prevalence of genital abnormalities (5). Thus stopping compulsory military service and its related medical check-up could have determined an important social impact in terms of a lower level of attention and care on male genital/sexual diseases and couples' infertility (6).

The aim of the present observational study was to check the prevalence of genital/sexual diseases among young male high-school students and compare these data with those obtained by Armed Forces Sanitary Service during the compulsory military service period preliminary medical check-up (MSMC) (5) and promote an alternative campaign of investigation among young students to reduce the risk of infertility and sexually transmitted diseases among future couples.

\section{Materials AND MEthods}

This is a prospective multi centre observational analytical cohort study on young male high-school students, specially those between 18 and 19 years old, organized under the aegis of the Italian Society of Andrology (SIA). Urologists from six different urological centres throughout Italy were involved in the study. High school head master assemblies were convened in each town to present the study project. Each of them thus organized a special student assembly to introduce a slide presentation by the urologists showing the most frequent unrecognized andrological and sexually transmitted diseases. In particular, pictures from subjects with different clinical cases of varicocele, hydrocele, preputial phymosis, ambiguous genitalia, hypospadia, micropenis, penile congenital curvature were shown to the students presenting all possible complications overall related to infertility. Women could participate in the assembly to obtain information on male genital diseases and exert a sort of counselling on male sexual partners inducing them to be evaluated by the urologist in a private consultation. All male students who were present at the assembly received the option of having a free clinical consultation either in a special room in the school the same morning or at the hospital thereafter. A smaller cohort of students who reported having had previous sexual intercourse, were then randomly selected to fill in an anonymous self-report questionnaire on the use of condoms, alcohol and drug abuse (Appendix 1). All of them signed the Informed Consent to participate in the study. The term "binge drinking" is the modern definition of drinking alcoholic beverages with the primary intention of becoming intoxicated by heavy consumption of alcohol over a short period of time.

Each male subject with evidence of andrological problems was counselled to receive subsequent adequate medical and/or surgical treatment.

\section{Statistical analysis}

The prevalence of genital/sexual diseases was calculated as the proportion of young male high-school students with genital/sexual diseases over the specified period of study time. The differences between each parameter were evaluated by using T-test or chi-square test when appropriate. Moreover, the Mann-Whitney test was also used to compare mean values of different parameters. Statistical significance was achieved if $\mathrm{p}$ was $<0.05$. All reported $\mathrm{p}$ values were two-sides. All statistical analyses were performed by using SPSS 11.0 for Apple Macintosh (SPSS, Inc., Chicago, Illinois).

\section{RESULTS}

12,535 students $(10,432$ males-83.6\%) followed the presentation. The mean number of male subjects explored in relation with the total number of males (all ages) per area was about 3\% (range 1-18,4\%). The rate of participation was also related to both the number of schools explored per-area and the regional territory extent. 4,897 males (46.7\%) decided to be checked-up by the urologist and 1554 (31.7\%) of them presented relevant andrological diseases potentially related to a reduced rate of fertility (Table 1 ). Thus the prevalence of andrological diseases among young male students was $31.7 \%$ (25.28\% if related x 100.000 subjects). The rate of male subjects asking for a medical consultation seemed to be strongly influenced and proportionally increased by the number of women present in the single class. When women exceeded $50 \%$ of the total students in the single class, about $90 \%$ of males accepted to be checked-up. In the class where the number of female students were less than $50 \%$, only $37.9 \%$ of male students underwent further urological controls ( $p<0.001$; $\mathrm{df}=2 ; \mathrm{F}=87.33$ ). A wide range of andrological diseases such as varicocele, testis hypotrophy, mobile testis, epidydimal cyst, phimosis, short prepucial frenulum, hypospadia, congenital penile curvature, ambiguous genitalia, micro penis were collected (Table 2). Among these hypospadia and disorders of sex development (pseudo-hermaproditism) had already been fully diagnosed. No significant differences between the prevalence of diseases and geographical area were found $(p=0.12$; $\mathrm{df}=2 ; \mathrm{F}=7.2$ ); the number of affected subjects enrolled in the study in different geographical areas ranged from 30.5 to $32.5 \%$ (mean $31.7 \%$ ) of evaluated males.

Five-hundred students completed the questionnaire concerning their lifestyle. Most them reported a continuous (35.2\%) or occasional (37\%) use of condom during sexual intercourse while $27.8 \%$ of them hadn't yet experienced condom use. About 90\% of condom users ascribed this practice to avoid undesired pregnancies in 
Table 1.

Distribution of check-ups in six different urological centres.

\begin{tabular}{|c|c|c|c|c|c|c|}
\hline City & Residents: reale/total & Subjects & Male & Female & Male-visits & Andrological diseases \\
\hline Florence & $170.737 / 365.881$ & 4434 & 3501 (78.9\%) & 933 (21.1\%) & $1545(44.1 \%)$ & $471(30.5 \%)$ \\
\hline $\begin{array}{l}\text { Rimini } \\
\text { Ferrara } \\
\text { Forlì }\end{array}$ & $\begin{array}{l}66.886 / 138.465 \\
62.590 / 133.980 \\
56.661 / 117.550\end{array}$ & 3831 & $3831(100 \%)$ & 0 & $1302(33.9 \%)$ & $418(32.1 \%)$ \\
\hline Savona & $28.868 / 61.916$ & 300 & $230(76.6 \%)$ & $70(23.4 \%)$ & 100 (43.4\%) & 31 (31\%) \\
\hline Biella & $21.508 / 46.128$ & 3970 & 2920 (73.5\%) & 1050 (26.5\%) & $1950(66.7 \%)$ & $634(32.5 \%)$ \\
\hline Total & $407.250 / 743.918$ & 12.535 & $10.482(83.6 \%)$ & $2053(16.4 \%)$ & 4897 (46.7\%) & $1554(31.7 \%)$ \\
\hline
\end{tabular}

Table 2.

The predominance of single diseases in 4897 male check ups.

\begin{tabular}{|c|c|c|c|c|}
\hline Pathology & Cases & $\%$ & Already diagnoses & $\%$ \\
\hline Varicocele & 857 & 17.5 & 29 & 3.3 \\
\hline Testis volume $<12 \mathrm{ml}$ & 61 & 1.2 & 0 & 0 \\
\hline Mobile testis & 202 & 4.1 & 0 & 0 \\
\hline Epidymal cysts & 57 & 1.1 & 0 & 0 \\
\hline Hydrocele & 24 & 0.5 & 5 & 20.8 \\
\hline Phimosis & 49 & 1 & 31 & 63.2 \\
\hline Short preputial frenulum & 160 & 3.2 & 14 & 8.7 \\
\hline Hypospadias & 16 & 0.3 & 16 & 100 \\
\hline Congenital penile curvature & 46 & 0.9 & 0 & 0 \\
\hline Disorders of sex development & 2 & 0.04 & 2 & 100 \\
\hline Inguinal hernia & 14 & 0.3 & 7 & 50 \\
\hline Micropenis & 5 & 0.1 & 0 & 0 \\
\hline Gynecomastia & 61 & 1.2 & 2 & 3.2 \\
\hline Testicular cancer & 0 & 0 & 0 & 0 \\
\hline Total & 1554 & $31.7 \%$ & 106 & $6.8 \%$ \\
\hline
\end{tabular}

Table 3.

Answers to an anonymous self-report questionnaire concerning student's lifestyle.

\begin{tabular}{|lrr|}
\hline Use of condoms & & \\
always & $176 / 500$ & $(36.2 \%)$ \\
seldom & $185 / 500$ & $(37 \%)$ \\
never used before & $139 / 500$ & $(27.8 \%)$ \\
\hline Reason & & \\
to avoid pregnancy in their partner & $325 / 361$ & $(90 \%)$ \\
to avoid the risks of sexual infections & $27 / 361$ & $(7.5 \%)$ \\
no answer & $9 / 361$ & $(2.5 \%)$ \\
\hline Drugs abuse & $198 / 500$ & $(39.6 \%)$ \\
cannabinoids & $132 / 198$ & $(66.6 \%)$ \\
cocain & $13 / 198$ & $(6.6 \%)$ \\
ecstasy+cannabinoids+cocain & $53 / 198$ & $(26.7 \%)$ \\
\hline Alchool use & $404 / 500$ & $(80.8 \%)$ \\
"binge-drinking" & $91 / 404$ & $(22.5 \%)$ \\
\hline Awareness of the term "specialist andrologist" & $65 / 500$ & $(13 \%)$ \\
\hline
\end{tabular}

their partners and $7.5 \%$ of them to avoid the risk of sexual infection transmission.

Drug abuse was reported by 198 out of 500 subjects (39.6\%) with current use of cannabinoids in $66.6 \%$ of cases, cocain $6.6 \%$, ecstasy mixed with cocain and cannabinoids $26.7 \%$. Alcohol consumption was documented in 404 out 500 subjects $(80.8 \%)$ but $22.5 \%$ of them only reported repeated "binge-drinking" episodes. The term "specialist andrologist" was known only by 65 out of 500 subjects (13\%) (Table 3).

\section{Discussion}

Currently, there are a great variety of health care evaluation indicators in relation with different clinical disciplines such as radiology, cardiology, geriatrics, pediatrics and many others (7). Andrology is a modern medical discipline that deals with male health, particularly relating to the problems of the male reproductive system and urological problems that are unique to men. It is the counterpart to gynaecology, which deals with medical 
issues which are specific to the female reproductive system (8). Females are usually well informed and documented about infertility and sexually related diseases while many males have an urgent need to be counselled for sexual dysfunctions often related to relational and subjective psychological problems (9). The term "andrologist" is currently known by 13\% of counselled males compared to $4 \%$ of males checked up during MSMC, although the number of men aware of their personal situation decreased from $10-20 \%$ found during MSMC $(5,10)$ to $6.8 \%$ found in the present study. Moreover previous studies demonstrated that andrological disorders were found in about 30\% of youngsters: these data have been confirmed by the mean rate of $31.7 \%$ found in the present series independently from the geographical area investigated.The logical explanation of this phenomenon could be that a lot of students are adequately informed on medical glossaries but not on their body health awareness to avoid subsequent complications on fertility and couples's sexual problems.

Hypospadia and disorders of sex development such as pseudo-hermaphroditism, have always already been diagnosed in all cases found in both military and school check-ups while less evident diseases such as penile congenital curvature and short prepucial fraenulum have been diagnosed just after a projection of slides session (11). About $1 \%$ of subjects showed a substantial reduction of testicular volume and all of them were counselled to check a second level visit to test the presence of complicated diseases such as Klinefelter Syndrome (KS) (karyotipe 47, XXY). The time of first diagnosis in patients with $\mathrm{KS}$ is essential to test germ cell degeneration due to the presence of additional chromosome $\mathrm{X}$ and planning an adequate sperm collection. In the past 10 years, our knowledge about fertility chances of patients with KS has changed considerably, especially when regarding the possibility of IVF ICSI treatment (in vitro fertilisation, intra cytoplasmic sperm injection) with single testicular spermatozoon. When entering puberty testicular volume of KS patients increases for a short time with rising testosterone and inhibin B levels at the same time. These decrease, however, and FSH increases during puberty. This seems to indicate a critical point in time when spermatogenetic function of the testicles could still be present. Thus, in early puberty there could possibly be a time slot when spermatozoa could be detected in the ejaculate or-if not-at least in the testicular tissue. These could be extracted by testicular sperm extraction, cryopreserved and used for intra cytoplasmic sperm injection therapy later on. In the literature, a total of 133 births of children from Klinefelter fathers have been reported. This early specific procedure could lead to a better acceptance of their diagnosis and also offer the option of not being incurably infertile (12).

The high number of male students who have accepted to be checked-up seemed to be strictly related and proportional to the number of female students in the same classroom. Female students are known to have a good perception of their bodies, careful to protect themselves against disease of all sorts, for future sexual activities. This could have determined a sort of inspiration for their male classmates to join the study. Thirty-five percent of evaluated subjects only reported a persistent use of condoms during sexual intercourses and only $7.5 \%$ of them used condoms to avoid infections. These data sound alarming in relation to the opportunity of avoiding sexually transmitted diseases such as infections from human immunodeficiency virus (HIV) and Human papilloma virus (HPV). Foresta et al. found HPV DNA in $10 \%$ young adult sperm cells who already had unprotected intercourse and its presence was associated with reduced sperm motility (13). Thus male infection could determine the spread of the disease related to different sexual partners. Due to these reasons the practice of safer sex, promoted in a sex-positive way, is necessary and should be included in a campaign of information directed at young male students. It includes the appropriate use of condoms (14). This is not just to prevent HIV, HPV and STDs, but also to prevent unwanted pregnancy, STI-related infertility, and cervical cancer (15). A multifaceted intervention program that provided information and skills, as well as counselling and services, appears to have positive influence on contraceptive practice and condom use among unmarried young females and males (16). Moreover the use of drugs (40\%) and alcohol (80\%) documented in our study could determine significant consequences on the students' health by reducing their sexual function and desire and representing the first cause of death among young people due to car accidents. Thus a good schoolbased prevention program should include a campaign on substance abuse related diseases.

Caria reported the effect of a new school-based prevention program against substance abuse on 7,079 students aged 12-14 years from 143 schools in seven European countries. The results demonstrated a subsequent decreased risk of alcohol-related problems (17).

Moreover Faggiano reported a persistent positive effect over 18 months for alcohol abuse and for cannabis use, but not for cigarette smoking on the same sample of 7,079 students (18). These data stressed the importance of information, since the check-up enforcement could be difficult and socially expensive. On the other hand, all these data suggest the need for national information campaigns by media and other communication strategies such as internet website browsers and social networks (19-20).

The World Wide Web is increasingly used by researchers, health care providers, and common people to seek medical information and could be also used to promote several opportunities of online communication, enhanced selfestimation, relationship formation, friendship quality, and sexual self-exploration (21-22).

\section{Conclusions}

Medical information remains one of the most useful tools to promote health. About 30\% of male young students have undiagnosed genital and sexual dysfunctions compared to women who normally have a clear and safe perception of their bodies. This implies the need of campaigns for information to promote sexual health and protect future couples' fertility. 


\section{APPENDIX 1}

\begin{tabular}{|c|c|}
\hline How old are you? & \\
\hline Do you use a condom? & $\begin{array}{ll}\square & \text { Always } \\
\square & \text { Seldom } \\
\square & \text { Never used before }\end{array}$ \\
\hline Why do you use a condom? & $\begin{array}{l}\square \text { To avoid pregnancy in your partner } \\
\square \text { To avoid the risks of sexual infections } \\
\square \text { No answer }\end{array}$ \\
\hline Do you use drugs? & $\begin{array}{l}\square \text { Yes } \\
\square \text { No }\end{array}$ \\
\hline If, yes, what kind od drugs? & $\begin{array}{l}\square \text { Cannabinoids } \\
\square \text { Cocain } \\
\square \text { Ecstasy } \\
\square \text { Cannabinoids + Cocain } \\
\square \text { Cannabinoids + Ecstasy } \\
\square \text { Cocain + Ecstasy } \\
\square \text { Cannabinoids + Cocain + Ecstasy }\end{array}$ \\
\hline Do you use alcohol? & $\begin{array}{l}\square \text { Yes } \\
\square \text { No }\end{array}$ \\
\hline What kind of alcohol? & $\begin{array}{l}\square \text { Wine } \\
\square \text { Beer } \\
\square \text { Spirits }\end{array}$ \\
\hline Do yu indulge in binge drinking? & $\begin{array}{l}\square \text { Yes } \\
\square \text { No }\end{array}$ \\
\hline Do you know the term "specialist andrologist"? & $\begin{array}{l}\square \text { Yes } \\
\square \text { No }\end{array}$ \\
\hline
\end{tabular}

\section{References}

1. Popay J, Bartley M, Owen C. Gender inequalities in health: social position, affective disorders and minor physical morbidity. Soc Sci Med. 1993; 36:21-32.

2. Mendoza-Sassi RA, Béria JU. Gender differences in self-reported morbidity: evidence from a population-based study in southern Brazil. Cad Saude Publica. 2007; 23:341-6.

3. Lai CH. Major depressive disorder: gender differences in symptoms, life quality, and sexual function. J Clin Psychopharmacol. $2011 ; 31: 39-44$.

4. Herlihy AS, Gillam L, Halliday JL, McLachan RI. Postnatal screening for Klinefelter syndrome: is there a rationale? Acta Paediatr. 2011; 100:923-33.

5. Mondaini N, Bonafe' M, Di Loro F, et al. Andrologic disease in a population of 18 years old young men during conscription screening: how many were a first diagnosis? Minerva Urol Nefrol. 2000; 52:63.

6. Mondaini N, Giubilei G, Rizzo M, Carini M. Whither the andrologic pathology of Italian lads with the end of medical check up to conscripts. Arch Ital Urol Androl. 2005; 77:121.
7. Sans-Corrales M, Pujol-Ribera E, Gené-Badia J, Pet al. Family medicine attributes related to satisfaction, health and costs. Fam Pract. 2006; 23:308-16.

8. Lenzi A, Jannini EA. The andrologist from medicine of reproduction to sexual medicine: the Italian experience. Int J Androl. 2005; 28(Suppl 2):9-13.

9. Adegunloye OA, Ezeoke GG Sexual dysfunction-A silent hurt: issues on treatment awareness. J Sex Med. 2011; 8:1322-9.

10. Campodonico F, Michelazzi A, Capurro A, Carmignani G. Andrologic disease detected during army medical visit. Arch Ital Urol Androl. 2003; 75:205.

11. Mondaini N, Ponchietti R, Bonafè M, et al. Hypospadias: incidence and effects on psychosexual development as evaluated with the Minnesota Multiphasic Personality Inventory test in a sample of 11,649 young Italian men. Urol Int. 2002; 68:81-5.

12. Kliesch S, Zitzmann M, Behre HM. Fertility in patients with Klinefelter syndrome (47,XXY). Urologe A. 2011; 50:26-32.

13. Foresta C, Garolla A, Zuccarello D, et al. Human papillo- 
mavirus found in sperm head of young adult males affects the progressive motility. Fertil Steril. 2010; 93:802-6.

14. Sartorius GA, Nieschlag E. Paternal age and reproduction. Hum Reprod Update. 2010; 16:65-79.

15. Kigbu JH, Nyango DD. A critical look on condoms. Niger J Med. 2009; 18:354-9.

16. Lou CH, Wang B, Shen Y, Gao ES. Effects of a community-based sex education and reproductive health service program on contraceptive use of unmarried youths in Shanghai. J Adolesc Health. 2004; 34:433-40.

17. Caria MP, Faggiano F, Bellocco R, et al. Effects of a school-based prevention program on European adolescents' patterns of alcohol use. J Adolesc Health. 2011; 48:182-8.

18. Faggiano F, Vigna-Taglianti F, Burkhart G, et al. EU-Dap Study
Group. The effectiveness of a school-based substance abuse prevention program: 18-month follow-up of the EU-Dap cluster randomized controlled trial. Drug Alcohol Depend. 2010; 108:56-64.

19. http://www.salute.gov.it/resources/static/focus/307/presentazione.pdf

20. Gosselin P, Poitras P. Use of an internet "viral" marketing software platform in health promotion. J Med Internet Res. 2008; 10:e47.

21. Tian H, Brimmer DJ, Lin JM, et al. Web usage data as a means of evaluating public health messaging and outreach. J Med Internet Res. 2009; 11:e52.

22. Valkenburg PM, Peter J. Online communication among adolescents: an integrated model of its attraction, opportunities, and risks. J Adolesc Health. 2011; 48:121-7.

\section{Correspondence}

Nicola Mondaini, MD (Corresponding Author) mondatre@hotmail.com

Tommaso Cai, MD

Riccardo Bartoletti, MD

U.O. Urology, S. Maria Annunziata Hospital,

University of Florence, Firenze, Italy

Mauro Silvani, MD

Department of Surgery, Division of Urology,

Ospedali degli Infermi, Biella, Italy

Teo Zenico, MD

U.O. Urology, Morgagni Pierantoni Hospital, Forlì, Italy

Fabrizio Gallo, MD

Franco Rosso, MD

Department of Surgery, Division of Urology,

San Paolo Hospital, Savona, Italy

Gianni Ughi, MD

Pasquale Scarano, MD

U.O. Urology, Civile Hospital, Rimini, Italy

Vincenzo Orlando, MD

Stabilimento Chimico Farmaceutico Militare, Firenze, Italy 